\title{
Clinical manifestations of autosomal recessive polycystic kidney disease (ARPKD): kidney-related and non-kidney-related phenotypes
}

\author{
Rainer Büscher • Anja K. Büscher • Stefanie Weber • \\ Julia Mohr • Bianca Hegen • Udo Vester • Peter F. Hoyer
}

Received: 26 April 2013 /Revised: 5 September 2013 / Accepted: 6 September 2013 /Published online: 10 October 2013

(C) IPNA 2013

\begin{abstract}
Autosomal recessive polycystic kidney disease (ARPKD), although less frequent than the dominant form, is a common, inherited ciliopathy of childhood that is caused by mutations in the PKHD1-gene on chromosome 6. The characteristic dilatation of the renal collecting ducts starts in utero and can present at any stage from infancy to adulthood. Renal insufficiency may already begin in utero and may lead to early abortion or oligohydramnios and lung hypoplasia in the newborn. However, there are also affected children who have no evidence of renal dysfunction in utero and who are born with normal renal function. Up to $30 \%$ of patients die in the perinatal period, and those surviving the neonatal period reach end stage renal disease (ESRD) in infancy, early childhood or adolescence. In contrast, some affected patients have been diagnosed as adults with renal function ranging from normal to moderate renal insufficiency to ESRD. The clinical spectrum of ARPKD is broader than previously recognized. While bilateral renal enlargement with microcystic dilatation is the predominant clinical feature, arterial hypertension, intrahepatic biliary dysgenesis remain important manifestations that affect approximately $45 \%$ of infants. All patients with ARPKD develop clinical findings of congenital hepatic fibrosis (CHF); however, non-obstructive dilation of the intrahepatic bile ducts in the liver (Caroli's disease) is seen at the histological level in only a subset of patients. Cholangitis and variceal bleeding, sequelae of portal hypertension, are life-threatening complications that may occur more often in advanced cases of liver
\end{abstract}

\footnotetext{
R. Büscher $(\bowtie) \cdot$ A. K. Büscher $\cdot$ S. Weber $\cdot$ B. Hegen • U. Vester • P. F. Hoyer

Children's Hospital, Pediatrics II, University of Duisburg-Essen, Hufelandstr. 55, 45122 Essen, Germany

e-mail: rainer.buescher@uk-essen.de

J. Mohr

Department of Pediatrics, HELIOS Klinikum Krefeld, Lutherplatz 40, 47805 Krefeld, Germany
}

disease. In this review we focus on common and uncommon kidney-related and non-kidney-related phenotypes. Clinical management of ARPKD patients should include consideration of potential problems related to these manifestations.

Keywords ARPKD · Extrarenal manifestation · Children · Hepatic fibrosis · Portal hypertension · Caroli's syndrome

\section{Introduction}

Autosomal recessive polycystic kidney disease (ARPKD) belongs to the family of cilia-related disorders and is an important inherited disease with distinct clinical features and genetics. In contrast to the relatively frequent autosomal dominant polycystic kidney disease (ADPKD), ARPKD is much rarer, with an incidence varying from approximately $1 / 10,000$ to $1 / 40,000$ live births in Caucasians [1-3]. It is generally diagnosed on the basis of clinical criteria, especially renal ultrasonography.

The organs that are primarily affected are the kidneys (polycystic kidneys) and liver (congenital hepatic fibrosis). In addition, several other extrarenal manifestations occur less frequently but can be observed at any age and disease stage $[2,4,5]$. The variability of organ involvement in ARPKD is not completely understood [6,7]; however, different combinations of mutations in the fibrocystin gene PKHD1 and its resulting changes in the fibrocystin/polyductin protein structure may at least partially explain the phenotypic variance $[7,8]$. It is widely recognized and corroborated by intrafamilial clinical variability among affected siblings that resulting ARPKD phenotypes frequently cannot be simply explained on the basis of the PKHD1 genotype. Phenotypes may also depend on the background of other genes, combinations of mutations or diseasemodifying genes, epigenetic factors, hormonal effects, and environmental influences $[6,7,9]$. However, severe phenotypes, such as neonatal demise, are more often associated with 
chain-terminating, truncating PKHD1 mutations than with moderate phenotypes, and the presence of two chainterminating mutations invariably results in perinatal lethality $[8,10]$. In contrast, amino acid substitutions are more commonly associated with nonlethal presentation, and the presence of at least one amino acid substitution is required for affected individuals to survive the perinatal period $[8,10]$.

Pulmonary hypoplasia, a serious complication that generally occurs as the result of oligohydramnios, is due to poor fetal urine output, leading to respiratory failure and neonatal death $[2,3]$. Almost $30 \%$ of affected newborns that present with large, echogenic kidneys die within the neonatal period owing to respiratory insufficiency $[2,3,9,11]$. Some patients that survive the neonatal period present with complications primarily associated with liver disease, such as portal hypertension $(\mathrm{PH})[3,4]$ and esophageal bleeding $[9,12,13]$, later in childhood and adulthood; others may progress to end-stage renal disease (ESRD) within the first decades of life [3]. Other associated comorbidities, such as systemic hypertension [4], renal failure [3, 14, 15], or chronic lung disease [11], can also occur when the children get older. As more patients with ARPKD survive to adulthood, liver and other complications are likely to become more prevalent, with hepatosplenomegaly being the predominant clinical finding [3].

The focus of our review is the broadened spectrum of the ARPKD phenotype beyond the kidney, with attention given to certain kidney-related and non-kidney-related manifestations (Fig. 1; Table 1).

\section{Hepatobiliary disease}

Autosomal recessive polycystic kidney disease is characterized by dysgenesis of the hepatic portal triad, which is associated with defective remodeling of the ductal plate, hyperplastic biliary ducts, and congenital hepatic fibrosis (CHF) (Fig. 2) $[13,16,17]$. Although these pathological changes are present at the microscopic level at birth, the significance of these findings is variable, and clinical and radiographic complications of CHF may become apparent at any time between birth and adulthood (Fig. 3) [16-18]. Liver manifestations may comprise the major symptomatic disease complications in older patients $[4,19]$. Fortunately, hepatocellular function is usually preserved early in the course of the disease. Subsets of patients develop Caroli disease, which is associated with recurrent cholangitis and risk of sepsis (Fig. 4). In some patients, particularly after the use of dialysis to treat ESRD due to the complete loss of renal function has resulted in impaired clearance of toxins that are shunted from the liver, complications of $\mathrm{CHF}$ and Caroli disease can result in $\mathrm{PH}$ and an increased risk of ascending cholangitis (Fig. 3) [3, 4]. Such patients demonstrate splenomegaly, hypersplenism with low platelet counts, and gastroesophageal varices with attendant risks of acute bleeding, and they are also at risk of developing bacteremic infections from both splenic dysfunction and cholangitis $[3,11,16]$. Patients with severe PH and dependent complications (e.g., gastroesophageal varices) may require porto-systemic shunting. Portal decompressive surgical shunts are uncommon in pediatric ARPKD patients and are only implanted at specialized transplant centers [20]. Because normal kidney function plays a pivotal role in ammonia disposal, porto-systemic shunting can be especially contraindicated in patients with impaired kidney function, unless they have successfully undergone kidney transplantation $[12,21]$.

In addition, after 40 years of age, adult ARPKD patients are at increased risk of developing benign and malignant liver tumors, particularly cholangiocarcinoma [16, 20]. Although this is not a significant problem while patients are in pediatric care, it may be important to be aware of this possibility when adolescents are transitioned to internists [20].

Extrarenal cysts are uncommon in pediatric patients and are more frequently seen in adults [22]. Liver cysts (Fig. 5) are more common in ADPKD patients and occur only rarely in ARPKD patients, although choledochal cysts have been reported in the latter group [2,12]. Gunay-Aygun and colleagues [23] performed ultrasound evaluations in 110 parents from 64 independent ARPKD families and identified multiple liver cysts in several parents, suggesting that carrier status of $P K H D 1$ mutations creates a predisposition for liver cysts. Furthermore, they suggest that ARPKD patients might have liver cysts that are continuous with the biliary tree, differing from the isolated cysts predominantly observed in ADPKD patients [23].

\section{Complications of liver disease: portal hypertension, esophageal varices, and variceal bleeding}

Although PH in ARPKD was not systematically studied in the past, it starts early in life and progresses over time [12, 13, 17]; $40-50 \%$ of infants surviving the first year of life will develop evidence of $\mathrm{PH}$ over time $[9,11]$. While renal disease diagnosed during the first year of life is most severe in neonates, many of the surviving patients develop sequelae from congenital hepatic fibrosis later in life, including hypersplenism, $\mathrm{PH}$, and variceal bleeding [13]. Despite these hepatobiliary complications, hepatocellular function is usually preserved for a long time, and patients are more likely to present with hematemesis or melena resulting from bleeding esophageal varices. PH can only be diagnosed clinically by the presence of splenomegaly, hypersplenism, or esophageal varices, the latter leading to acute variceal bleeding. Platelet count is a good surrogate marker of PH severity [13]. Sonographic evidence of PH is characterized by visualization of the portal vein, decreased blood flow in the portal vein with minimal undulation, splenomegaly, and the presence of varices (Fig. 3) $[24,25]$. In a recent paper, Gunay-Aygun and colleagues used 
Fig. 1 Schematic of kidneyrelated and non-kidney-related manifestations of autosomal recessive polycystic kidney disease (ARPKD)

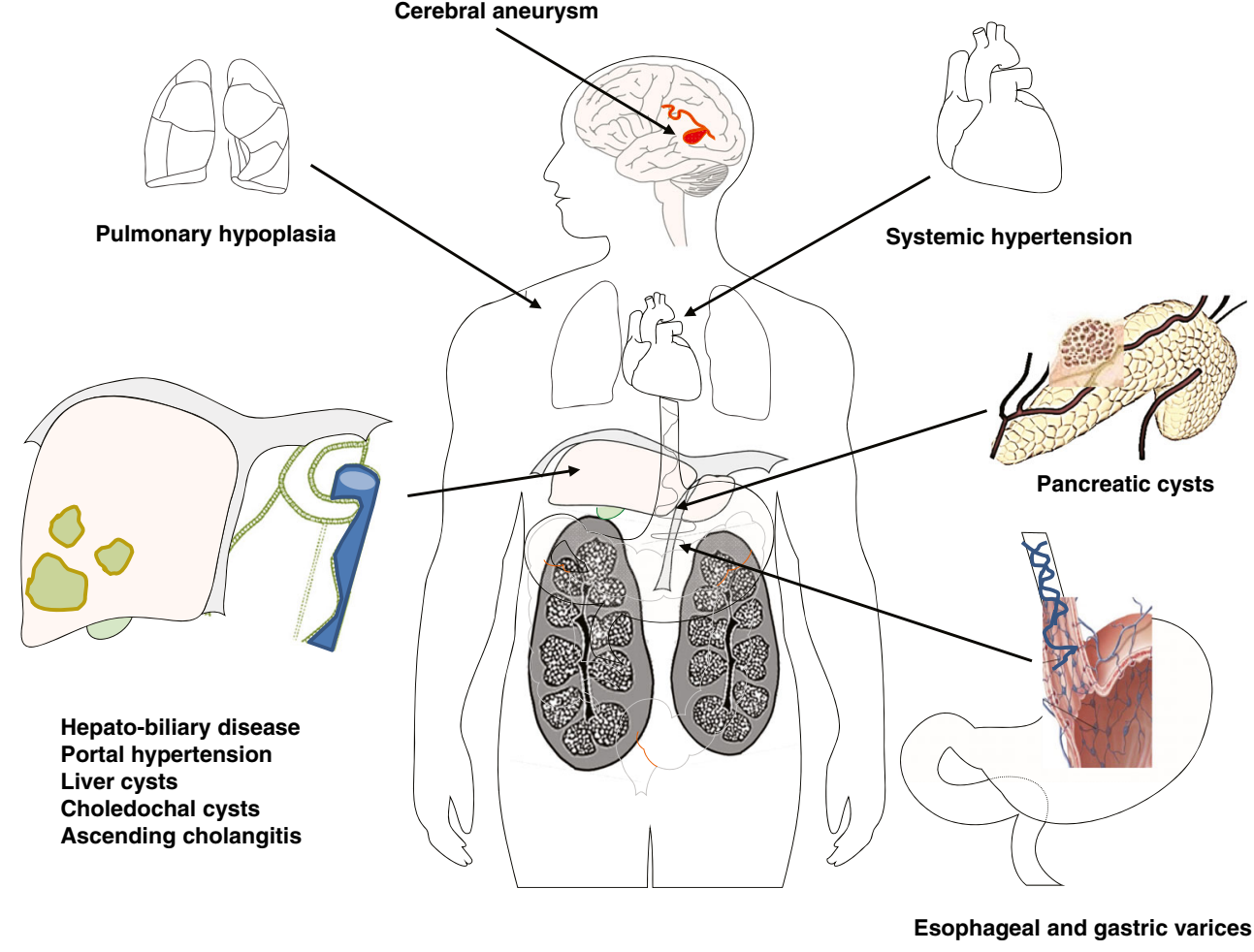

the spleen length:height ratio and spleen volume to evaluate the severity of PH in ARPKD and to understand its characteristics [13]. Interestingly, they found that the pathophysiology of PH in ARPKD is established early in life; $60 \%$ of patients aged $<5$ years had splenomegaly, an incidence rate that was not significantly different from the incidence in older children and adults. The number of patients that came to medical attention because of splenomegaly and thrombocytopenia was low, which suggests that the number of patients diagnosed with ARPKD on the basis of PH is also low.

The frequency of esophageal varices ranges from 5 to $37 \%$ $[9,12,25]$, making it a relatively common complication (Fig. 6; Table 1). In a meta-analysis of 1,230 patients with CHF, Srinath et al. report varices in 164 cases (13\%) and bleeding varices in 74 cases (6\%) [12]. However, one must be very careful when interpreting the frequency of these extrarenal manifestations because they are derived from studies with few patients or based on single-center observations [9, 12, 25]. Prevention of recurrent esophageal bleeding is the primary treatment goal in all ARPKD patients - especially in children with any signs of PH. Therefore, regular esophago-gastro-duodenoscopy should be performed at least once annually in children that are at risk for bleeding varices [20]. Endoscopic bind ligation (EBL) has a very low complication rate and can therefore be effective in patients with varices and esophageal bleeding. Cyanoacrylate glue can also be used in children; however, little is known about its efficacy in ARPKD patients at the present time. Sclerotherapy is seldom used as method of choice because it has a much higher complication rate. Although data derived from adult studies suggest that propranolol may decrease the mortality rate associated with $\mathrm{PH}$, unselective $\beta$-blockade is not recommended because insufficient data are currently available on the prevention of esophageal bleeding in children with ARPKD [20]. Some patients with severe signs of $\mathrm{PH}$ and splenomegaly are resistant to any kind of primary prophylaxis or treatment. In such cases, portal decompressive surgical shunts, although uncommon in children, may become necessary [20].

\section{Kidney function and liver disease}

The treatment of kidney and liver involvement in ARPKD during the past decades has focused first on renal complications (e.g., treatment of problems derived from ESRD, dialysis, and transplantation), followed by complications derived from hepatobiliary disease. Studies performed over the past years have revealed that significant hepatobiliary disease may lead to severe pre- or post-transplant problems that can adversely affect outcomes [20]. It is suggested that approximately $40 \%$ of affected ARPKD children present a severe combined renal/hepatobiliary phenotype [20]. Therefore, it is only fitting that modern strategies focus on new clinical approaches for these severely affected children that take both renal and hepatic problems into account.

A few groups have systematically analyzed the possible correlation between renal- and biliary-related morbidities, with heterogeneous results [11, 26, 27]. While earlier findings suggested that the survival of children with moderate renal 
Table 1 Frequency of kidney-related and non-kidney-related manifestations in autosomal recessive polycystic kidney disease ${ }^{\mathrm{a}}$

\begin{tabular}{|c|c|c|c|}
\hline Extrarenal manifestation & Frequency & Therapeutic options & Reference \\
\hline $\begin{array}{l}\text { Caroli disease - a variant } \\
\text { phenotype of the ductal } \\
\text { plate malformation }\end{array}$ & $16-26 \%$ & $\begin{array}{l}\text { Liver transplantation or combined liver and kidney transplantation } \\
\text { (when severe sequelae with significant renal failure) }\end{array}$ & {$[1,11,16,19,25]$} \\
\hline Hepatic fibrosis & $31 \%$ & $\begin{array}{l}\text { Liver transplantation or combined liver and kidney transplantation } \\
\text { (when severe sequelae with significant renal failure) }\end{array}$ & {$[1,11,16]$} \\
\hline Hepatosplenomegaly & $21-52 \%$ & $\begin{array}{l}\text { Liver transplantation or combined liver and kidney transplantation } \\
\text { (when hepatosplenomegaly results from hepatic fibrosis and } \\
\text { severe sequelae with significant renal failure occur) }\end{array}$ & {$[9,12,25]$} \\
\hline Liver cysts & Unknown & Cystectomy if risk of rupture & {$[36,50]$} \\
\hline Pancreatic cysts & Unknown & Cystectomy if risk of rupture & {$[36]$} \\
\hline Portal hypertension & $15-44 \%$ & $\begin{array}{l}\beta \text {-blockers???; endoscopic band ligation; sclerotherapy; portosystemic } \\
\text { shunting }\end{array}$ & {$[9,11,17,25,40]$} \\
\hline $\begin{array}{l}\text { Systemic hypertension } \\
\text { (\% on drug treatment) }\end{array}$ & $65-75 \%$ & $\begin{array}{l}\text { Preferred drugs: ACE-inhibitors; angiotensin II receptor inhibitors; } \\
\text { sometimes multidrug therapy is required }\end{array}$ & {$[9,11]$} \\
\hline Choledochal cysts & Unknown & - & {$[36]$} \\
\hline Esophageal varices & $5-3 \%$ & $\begin{array}{l}\text {-Regular EGD monitoring in patients with PH } \\
\text {-EBL } \\
\text {-Sclerotherapy (higher complication rate!) } \\
\text {-Propranolol alone or in combination with EBL decreases mortality in } \\
\text { adults (no pediatric studies) } \\
\text {-Cyanoacrylate glue }\end{array}$ & {$[9,12,25]$} \\
\hline Ascending cholangitis & $\begin{array}{l}1-65 \% \\
(6 \% \text { for CHF and } 65 \% \\
\quad \text { for Caroli disease) }\end{array}$ & $\begin{array}{l}\text {-Parenteral antibiotics as soon as high fever/sepsis occurs } \\
\text {-Synthetic bile acids (ursodiol, no controlled studies) } \\
\text {-Liver transplantation/-Combined liver and kidney transplantation } \\
\text { (when significant renal failure and recurrent cholangitis occur) } \\
\text { Preferred drugs: ACE-inhibitors; angiotensin II receptor inhibitors; } \\
\text { sometimes a multidrug therapy is required }\end{array}$ & {$[11,12,20,51]$} \\
\hline Cholangiocarcinoma & $<1-6 \%$ & Liver transplantation & {$[12,20,51]$} \\
\hline Chronic lung disease & $12 \%$ & - & [11] \\
\hline Cerebral aneurysm & $<1 \%(5-10 \%$ in ADPKD $)$ & Interventional occlusion & {$[52-54]$} \\
\hline
\end{tabular}

ACE, Angiotensin converting enzyme; ADPKD, autosomal dominant polycystic kidney disease; CHF, congenital hepatic fibrosis; EBL, endoscopic bind ligation; EGD, Esophago-gastro-duodenoscopy; PH, portal hypertension

${ }^{a}$ The percentages of the manifestation of kidney-related and non-kidney-related complications are derived from several studies in the field and are based on larger scale studies and single-center observations

disease might lead to more severe liver disease later on [27], other studies did not find a correlation between renal and biliary involvement $[11,26]$. International longitudinal studies are underway to evaluate whether renal and liver disease in ARPKD patients develop independently or whether they are directly related comorbidities.

To determine whether the severities of kidney and liver disease were correlated, Gunay-Aygun and colleagues compared the spleen volumes of patients with severe kidney involvement to those of patients with mild kidney involvement [13]. They found that the mean spleen volume of patients with corticomedullary involvement (both renal cortex and medulla were abnormal on the ultrasound scan) was similar to that of patients with only medullary kidney disease (renal medulla was abnormal but cortex was normal on the ultrasound scan). However, the glomerular filtration rate correlated with spleen volume and was lower in patients with splenomegaly than in patients without splenomegaly. These authors considered that this finding is due to the progression of both kidney and liver disease. Similarly, the extent of cystic renal disease was similar between groups [13].

\section{Systemic hypertension}

Treatment for ARPKD is focused on minimizing and treating the long-term complications of kidney and liver disease, including hypertension, chronic kidney disease, $\mathrm{PH}$, varices, ascending cholangitis, and liver failure [2]. Systemic hypertension, which usually develops within the first few months of life, affects up to $80 \%$ of ARPKD children $[9,11]$. It is very common in both infants and adolescents [4], even in patients with normal renal function, and the majority of children with ARPKD are severely affected $[11,14]$. The pathogenesis of systemic hypertension in ARPKD is not completely understood. While some investigators assume that volume overload is associated with poor renal function and may therefore be a causative factor $[26,28]$, other groups observed a frequent 
Fig. 2 Schematic illustration showing the types of ductal plate malformations depending on the duct size affected. Left Normal bile ducts surround the portal vein (a), right abnormal ductal plate remodeling $(b)$, which results in dilated bile ducts and fibrosis in congenital hepatic fibrosis (CHF)

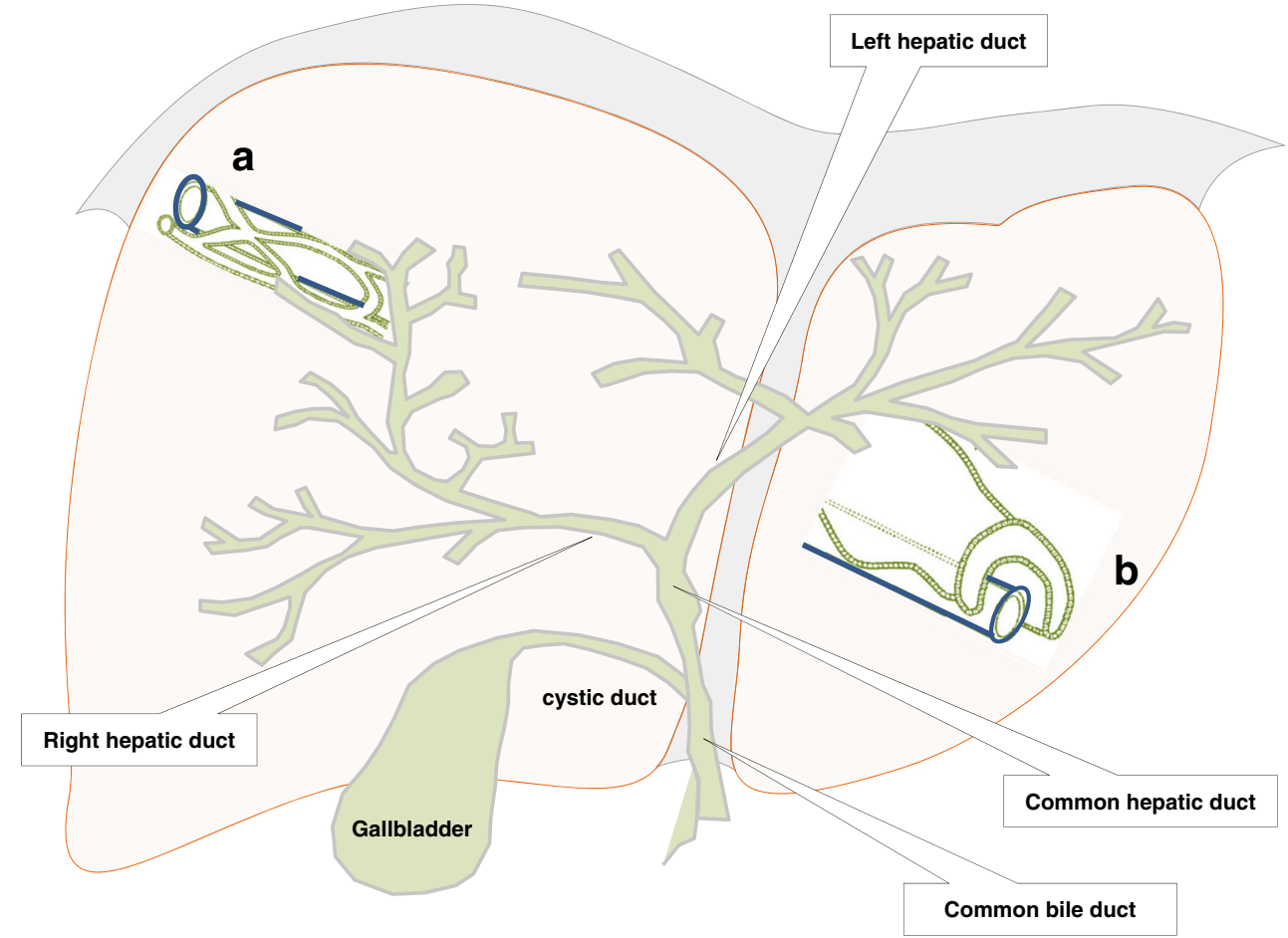

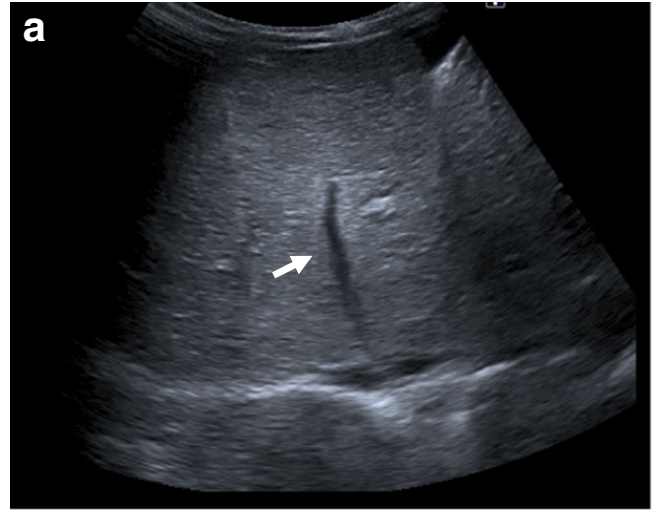

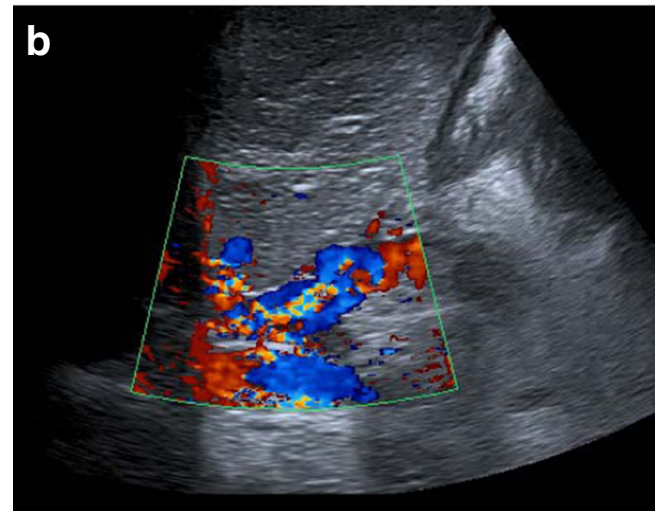

Fig. 3 Ultrasound and color Doppler image of a 2-year-old girl with autosomal recessive polycystic kidney disease (ARPKD) and congenital hepatic fibrosis (CHF). a Echogenic liver parenchyma and thickened periportal space (arrow) consistent with fibrotic remodeling, $\mathbf{b}$ a decreased blood flow in the portal vein with minimal undulation consistent with portal hypertension onset of severe hypertension within the perinatal period in combination with hyponatremia $[11,25,28,29]$. To further investigate the concept that hypertension results from the defective dysregulation of sodium reabsorption in the ectactic collecting ducts, Satlin and colleagues studied fluid composition in an ARPKD mouse model and explanted kidneys from ARPKD patients [29]. Although these researchers observed increased $\mathrm{Na}^{+}$reabsorption rates in the collecting ducts of renal epithelial cells (which led to systemic hyponatremia), the $\mathrm{Na}^{+}$-absorptive pathways were intact in renal epithelial cells derived from human ARPKD kidneys [29], indicating that hyponatremia was unlikely to influence the genesis and maintenance of hypertension. The observation that only high doses of the epithelial $\mathrm{Na}^{+}$channel inhibitor amiloride were able to modestly inhibit $\mathrm{Na}^{+}$reabsorption also does not support this theory [29]. Furthermore, a number of other studies also failed to demonstrate a link between hyponatremia, intravascular volume expansion, and low renin levels $[14,26]$. As in ADPKD [30], the renin-angiotensin system (RAS) may function as a key regulator of blood pressure; however, only limited data exist on RAS activation in ARPKD [31]. It is assumed that the fluid-filled cysts cause a reduction in blood flow to which the body tries to respond by releasing angiotensin II (ANG II) followed by vasoconstriction [31].

Hypertension can be difficult to control in affected children and may require multidrug treatment. Angiotensin-converting enzyme (ACE) inhibitors are the standard of care in ARPKD patients, although they have never been formally studied [2]. Studies in an ARPKD rat model suggest that increased intrarenal expression of the RAS components, renin, ACE, 
Fig. 4 Axial (a) and coronal (b) T2-W magnetic resonance (MR) images of a 12-year-old boy with autosomal recessive polycystic kidney disease (ARPKD) and Caroli syndrome following renal transplantation. Both scans show an enlarged liver and spleen and several cystic dilatations of the intrahepatic biliary ducts (arrow), especially in liver segment 7
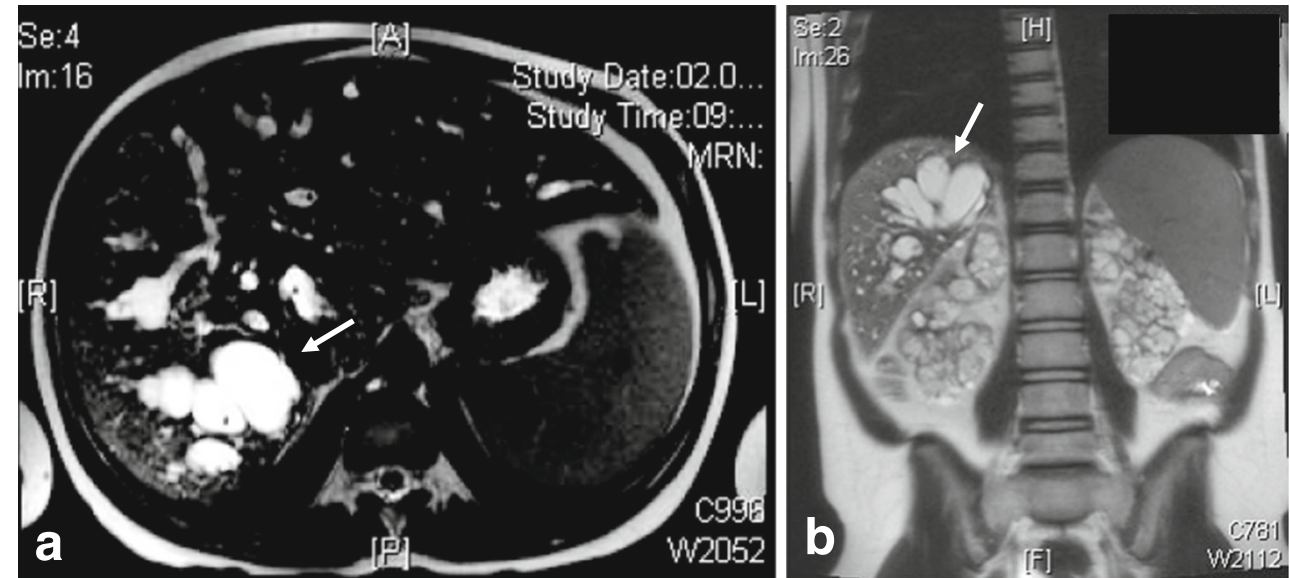

and ANG II is a feature of cystic kidney disease in the PCK rat, although ANG I and ANG II levels were not elevated [31]. Therefore, while the current standard for hypertension management in ARPKD patients includes ACE inhibitors and calcium channel blockers, the mechanism of action of these agents in controlling ARPKD-related hypertension remains unclear. We are aware that some clinicians avoid cAMP agonists, such as calcium channel blockers. However, this avoidance is based on preclinical, experimental studies, and serious side effects of calcium channel blockers in ARPKD patients have never been demonstrated in vivo. Some studies conducted in hypertensive ADPKD patients did not find any beneficial effects of ACE inhibitors or calcium channel blockers when compared with $\beta$-blockers, based on the effects of blood pressure control and prevention of the decline of renal function [32]. Other ADPKD trials have investigated whether combined treatment with ACE inhibitors and angiotensin receptor blockers is superior to ACE inhibitor monotherapy. Many of those studies are underpowered, have only

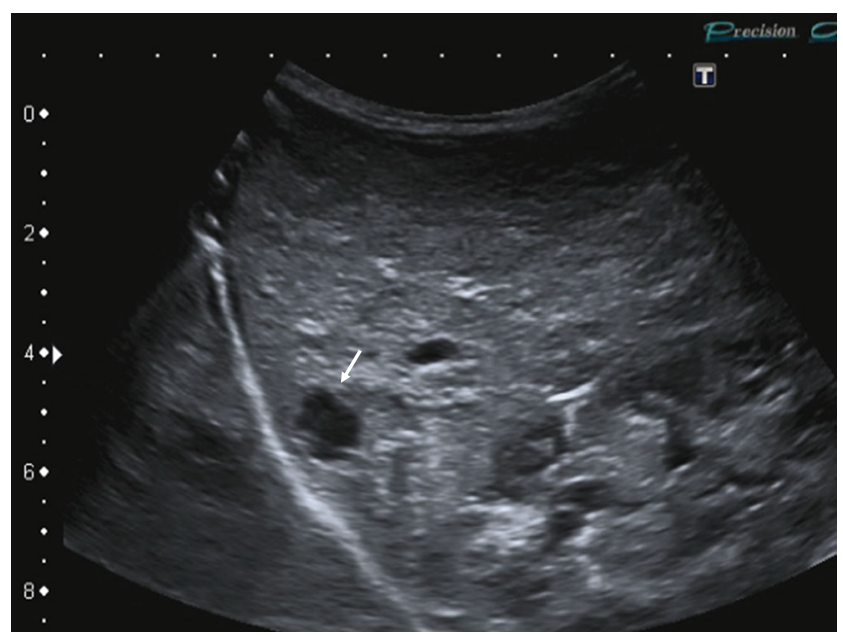

Fig. 5 High-resolution coronal ultrasound scan of a liver macrocyst (arrow) of a 1-year-old boy with autosomal recessive polycystic kidney disease (ARPKD)
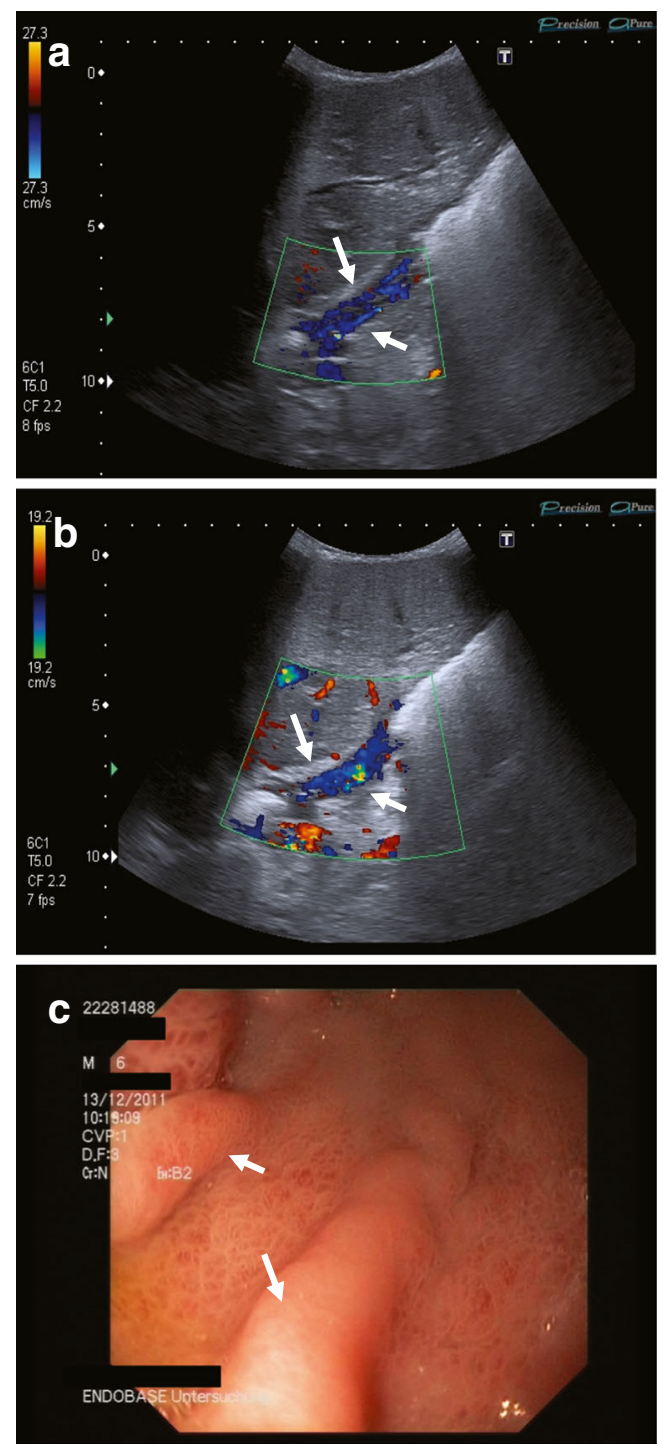

Fig. 6 Color Doppler ultrasound image of a 8-year-old boy with autosomal recessive polycystic kidney disease (ARPKD) and esophageal and gastric varices. a, b Multiple vessels along the esophagus (arrows) consistent with portal hypertension, $\mathbf{c}$ enlarged varices in the esophageal duodenal gastroscopy 
short follow-up periods, or fail to determine an appropriate endpoint [32]. However, hypertension should be treated early and aggressively in order to prevent severe sequelae of hypertension, such as congestive heart failure and stroke.

\section{Pancreatic cysts}

Fibrocystin/primary cilia-dependent mechanisms may also be centrally involved in the development of the pancreatic duct. Few studies have examined the structure and function of the exocrine pancreas in ARPKD model systems, such as PCK rats [33]. In their analysis of bile samples obtained from PCK rats, Yi and colleagues found irregularly dilated pancreatic ducts and observed higher luminal pressure [33]. Although pancreatic cysts occur more frequently in ADPKD patients $[34,35]$, they are not solely an extrarenal manifestation in ADPKD, and post-mortem analysis has also revealed pancreatic cysts in ARPKD patients (Table 1) [36]. In our own experience, we treated a 16-year-old boy with ARPKD and a genetically confirmed PKHD1 mutation who developed large pancreatic cysts 3 years after combined liver and kidney transplantation (Fig. 7).

\section{Pulmonary hypoplasia}

Pulmonary hypoplasia is the leading cause of death during the perinatal/neonatal period. Approximately $30 \%$ of affected children diagnosed with ARPKD die shortly after birth from respiratory distress as a result of limited diaphragmatic excursion, pulmonary hypoplasia, and thoracic compression caused

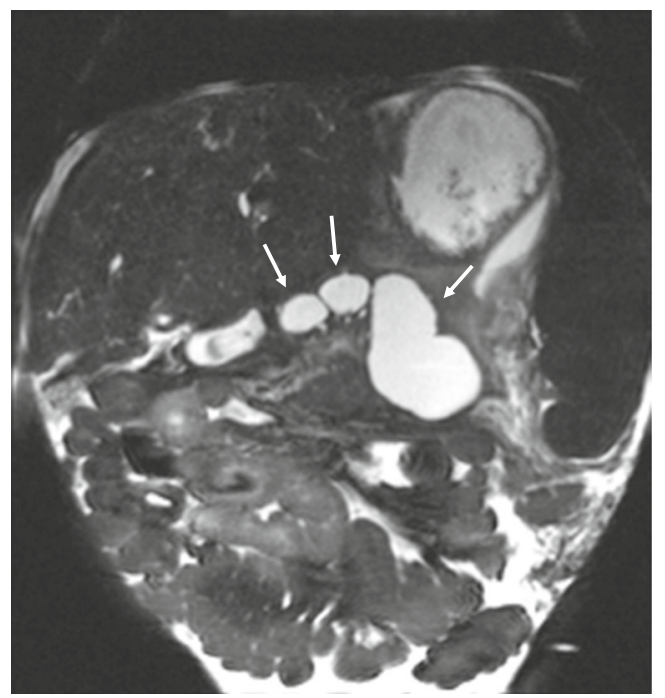

Fig. 7 Axial T2-W MR image of pancreatic corpus and tail cysts (arrows) in a 16-year-old boy with autosomal recessive polycystic kidney disease (ARPKD) following combined liver and kidney transplantation 3 years ahead. The largest cyst in the pancreatic tail measures $3.6 \times 4.8 \mathrm{~cm}$ by bilateral kidney enlargement (Fig. 8) [2, 9, 11]. Concurrent pulmonary infections may also lead to a higher mortality rate $[2,9,11]$. In their investigation of respiratory and general outcomes in neonates with renal oligohydramnios, Mehler et al. found that the cohort with renal agenesis/dysplasia exhibited the worst survival rates $(30 \%)$ and those with obstructive uropathies were associated with the best survival rates (84\%); in comparison, patients with ARPKD exhibited survival rates that were intermediate [37]. These results suggest that nonsurvival may be associated with the type of primary renal diagnosis [37].

In a series comparing the outcomes of patients with a history of oligohydramnios, Klaasen and colleagues [38] found that renal oligohydramnios was diagnosed earlier in non-survivors (cut-off point 30 weeks). Although the exact manifestation in utero is difficult to detect, this seems to be the
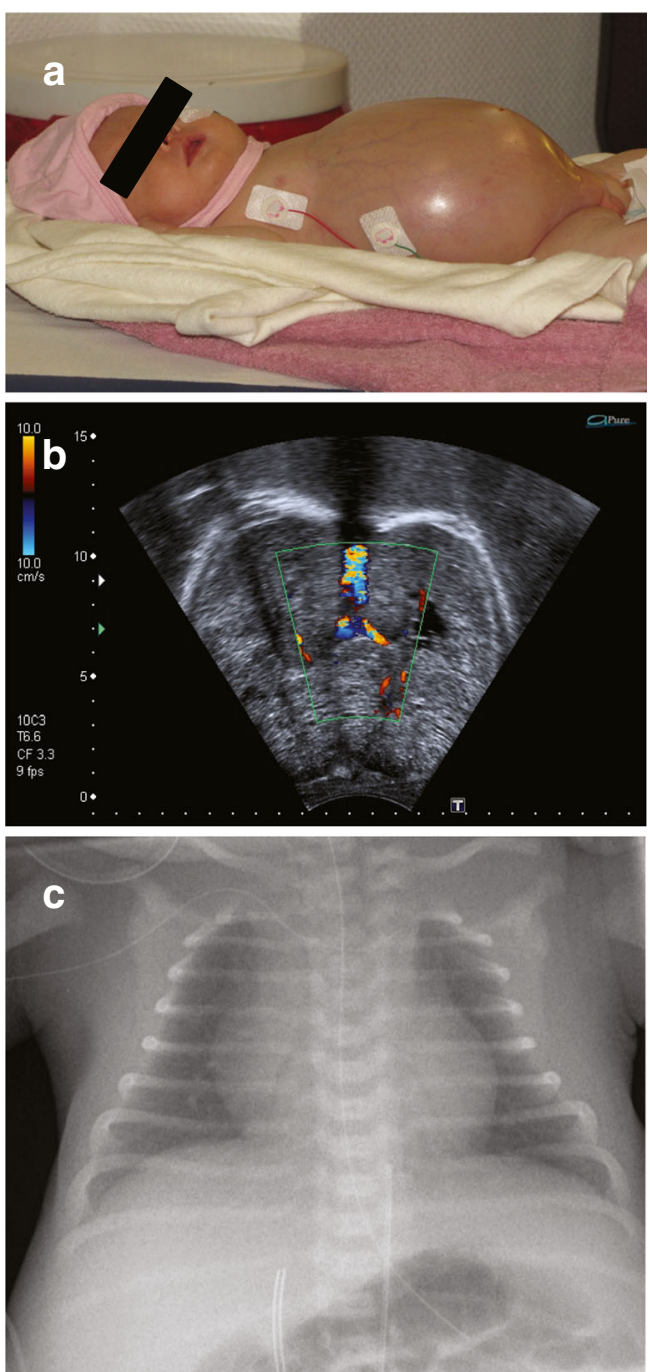

Fig. 8 Ten-day-old preterm infant (34th week) with autosomal recessive polycystic kidney disease (ARPKD) a Voluminous kidneys leading to respiratory problems, b, c High-resolution coronal ultrasound (view from caudal to cranial) (b) and thoracic X-ray (c) show enlarged kidneys and extreme pulmonary hypoplasia 
most critical prognostic factor in neonates. Earlier detection of amniotic fluid reduction appears to be associated with more severe pulmonary hypoplasia and might therefore be an indicator of poor outcome [37]. This does not automatically mean that any intervention that increases the amniotic fluid will lead to a beneficial outcome; in this study, neither vesicoamniotic shunting nor amnioinfusion had any effect on respiratory outcomes or general survival, and both procedures are controversial [38]. Aside from experimental settings in transgenic mouse models with oligohydramnion, it remains unclear which renal factors are required for "normal" pulmonary development [39]. Thus far, the existence of a "renal growth factor" that is required for adequate pulmonary development during early embryonic development has only been theoretically assumed in animal models [39]. Along with the anatomical preconditions of the neonatal thorax in patients with ARPKD, mechanical ventilation is another serious threat that is associated with, but is not a direct cause of, a higher mortality rate compared with non-ventilated newborns [11]. The mortality rate is associated with more severe pulmonary hypoplasia, which leads to a need for mechanical ventilation.

According to the PKD database, approximately $40 \%$ of all ARPKD neonates in the USA require mechanical ventilation during the first days of life [11]. However, the accurate percentage of ventilated neonates is certainly higher, since GuayWoodford and colleagues only reported those patients referred by a pediatric nephrologist and did not capture all ARPKD neonates [11]. Individuals with an early lethal form of ARPKD are therefore not included in the database. Furthermore, neonatal ventilation was also strongly associated with an earlier onset of the development of hypertension or chronic renal failure [11]. Pediatricians should keep in mind that mechanical ventilation is a procedure that should be utilized appropriately and for as brief a duration as possible.

\section{Treatment options for kidney-related and non-kidney-related complications}

There is currently no cure for ARPKD. Treatment focuses on managing the clinical complications derived either directly or indirectly from this disease, such as pulmonary hypoplasia, chronic renal insufficiency, arterial hypertension, and liver/ biliary disease. The clinical management of problems related to extrarenal manifestations in ARPKD is complex, lacks evidencebased experience, and is therefore certainly not easily resolved by any form of treatment algorithms. Because there is only limited prevalence of this problem, all clinical approaches must be individualized to specific complications [17]. Furthermore, whether and when an intervention must be performed requires careful analysis based on the results of screening evaluations.

The treatment of biliary disease is particularly problematic. The relatively high number of asymptomatic infections (e.g.,
$65 \%$ of patients with Caroli disease have a high risk of ascending cholangitis [20]) raises the question of whether antibiotic prophylaxis is indicated to prevent cholangitis [17, 20]. Because the duration of such antibiotic prophylaxis remains highly speculative, some authors suggest that children with biliary disease should receive prophylaxis with trimethoprim-sulfamethoxazole near the time of renal transplantation and during the early post-transplant period [17]. However, there is no good evidence that any kind of prophylaxis is effective, and this decision certainly depends on the clinical experiences of individual centers [17]. Physicians should be aware of the high mortality rate caused by Gram-negative sepsis in untreated ARPKD patients with severe liver disease.

Manifestation of PH is another serious problem that must be resolved carefully. Most centers advise their patients to undergo endoscopy routinely in order to prevent or treat complications arising from gastro-esophageal varices. In this case, treatment with propranolol alone or in combination with EBL and sclerotherapy as an alternative to EBL are adequate approaches and are considered to be primary prophylaxis $[17$, $20,40]$. The use of non-selective beta-blockers, although successful in adult patients with esophageal varices, is generally not recommended in children because there is insufficient data regarding the prevention of esophageal bleeding [20]. Although primary prophylaxis focuses on the prevention of esophageal bleeding, advanced cases of $\mathrm{PH}$ with splenomegaly may require more aggressive methods, such as portosystemic shunts. However, because data from prospective studies are lacking, no form of portal decompressive surgery is currently considered to be the method of choice in ARPKD children, and such an approach should be performed only at centers with highly skilled medical specialists. In the largest reported series of ARPKD patients with advanced CHF, the most common procedure was a splenorenal shunt [12]. However, owing to consecutive hyperammonemia and an increase in renal ammonia disposal in response to decreased hepatic detoxification, this intervention has recently been associated with a high risk of hepatic encephalopathy in patients who in the short term progressed to ESRD [21]. Because normal kidney function is central to ammonia disposal, portosystemic shunting cannot be recommended for anephric patients or those with ESRD unless they have already successfully undergone kidney transplantation $[12,21]$.

Although liver disease in ARPKD is generally not associated with clinically significant hepatocellular dysfunction, it is essential to determine the optimum point for the patient to undergo combined liver/kidney transplantation (CLKT) or sequential transplantation of liver and kidney when complications like PH have already occurred [17, 41, 42]. No general guidelines for CLKT in ARPKD patients have been established at this time. In fact, morbidity and mortality are higher after CLKT than in isolated kidney transplantation alone [43]. Although this balance might favor isolated kidney transplantation, remaining 
problems that arise from severe $\mathrm{PH}$ and cholangitis are a major threat to patients' survival and suggest that CLKT should be the first treatment option [43]. Despite other problems, CLKT from the same donor may also improve long-term kidney function over isolated kidney or liver transplantation alone. Therefore, a therapeutic decision regarding which transplant method is the best is multifactorial and should be discussed with all experts at the center, the patient, and the parents.

Systemic hypertension is very common in neonates, infants, and adolescents. It affects approximately $80 \%$ of all ARPKD patients $[9,11]$ and has a major impact on cardiovascular comorbidities, such as stroke, left ventricular hypertrophy, and congestive heart failure [2-4]. Therefore, strict blood pressure control is required. Although hypertension generally responds well to ACE inhibitors or ANG II receptor inhibitors, many ARPKD patients require several medications to control blood pressure [2-4]. Because controlled trials in ARPKD patients with respect to antihypertensive drug choice, dose, and degree of blood pressure control are missing, clinical experiences are gained from such studies performed in ADPKD patients. However, it should be noted that we are generalizing findings from controlled trials in ARPKD patients without any scientific basis. Therefore, controlled drug trials that focus on ARPKD patients are also necessary.

During the past decade, research on the pathogenesis of cystic development and the identification of the underlying genotypes/phenotypes has allowed the development of new therapeutic options [32]. The goal of several novel pharmacologic therapies is to slow the progression of cystic development in kidney and biliary ducts [2, 32, 44]. These novel therapeutic agents block the epidermal growth factor receptor (EGFR), block the vasopressin 2 receptor (V2R), or inhibit the mTOR receptor pathway $[2,45,46]$. The somatostatin analog octreotide has recently been shown to reduce hepatorenal cystogenesis in rodent models; it might also be beneficial in treating polycystic kidney and liver disease [47]. While some of these drugs are highly effective in animal models [2, 45, 46, 48], others show a potential effect only in kidney disease and not in liver disease (e.g., V2R antagonists) [32, 44]. Other groups found that EGFR inhibitors lacked efficacy and were moderately toxic in an animal model orthologous to human ARPKD [44]. These findings limit the therapeutic value of these pharmacologic therapies, at least when used alone [44]. Another problem is that various animal models and human trials were performed in the context of ADPKD and not in ARPKD. For example, targeted inhibition of mTOR has been proven to be effective in various animal models of ADPKD; however, sirolimus failed to attenuate the progression of kidney and liver disease in an ARPKD rat model [49]. It is not clear whether this effect is due to intrinsic or acquired rapamycin resistance in this animal model of ARPKD.

Despite all of the initial optimism, the translation of animal studies into clinical trials requires appropriate parameters to measure outcome, such as decreased renal volume and hepatorenal cystogenesis. This requirement is sometimes difficult to achieve in humans. Although some of the drugs have advanced to phase III clinical trials in adult ADPKD patients, the findings have not been encouraging, and these therapeutic options require further clinical observations before they become suitable for children with ARPKD [2].

\section{Conclusions}

Autosomal recessive polycystic kidney disease has variable clinical expression, and extrarenal manifestations occur more frequently than previously suggested. While the current understanding is that the formation of cystic structures is more evident in the dominant form of PKD and that patients with recessive PKD normally develop only dilatation of bile ducts, "real cysts" can also be present in some cases of ARPKD. The pathophysiological background of the various clinical side effects of ARPKD is not fully explained and prognostic markers of disease progression are unknown; however, extrarenal manifestations do occur more frequently in survivors of the neonatal period, manifesting later in adulthood. This information may become relevant when patients are transitioned to the care of internists.

Although there is currently no cure for ARPKD, there are encouraging research trials under way. The translation of results from animal studies into clinical trials requires appropriate parameters to measure outcomes. Many new drugs that seem to slow the progression of cystic development in the kidney and biliary tract have been successful in animal studies but not in human ones or are still in the clinical trial stage. Furthermore, the high morbidity and mortality of the disease require an international database to provide more information on extrarenal manifestations and their treatment options.

\section{Multiple choice questions (answers are provided following the reference list)}

1) Extrarenal complications of ARPKD include:

a. Interrupted aortic arch

b. Caroli disease

c. Colonic diverticula

d. Inguinal hernia

e. Cardiac valve disease

2) What percentage of children that survive the neonatal period will develop evidence of portal hypertension over time?

a. Almost every child

b. Close to $0 \%$

c. Almost $50 \%$

d. Depending on the clinical database, 10-15\% 


\section{e. Close to $95 \%$}

3) What is the pathogenesis of systemic hypertension in ARPKD?
a. Volume overload
b. Combination with hyponatremia
c. Excessive release of angiotensin II followed by vasoconstriction
d. Poor renal function
e. All of the above are possible explanations

4) Which is the wrong answer? Treatment options of gastroesophageal varices in children with ARPKD include:
a. Regular EGD monitoring in patients with $\mathrm{PH}$
b. Esophageal band ligation
c. Sclerotherapy
d. Non-selective beta-blockers
e. Cyanoacrylate glue

5) Which is the wrong answer? Contributing factors to the disease phenotype in ARPKD include:
a. Hormonal effects (estrogens)
b. Combination of mutations
c. Disease-modifying genes
d. Mutation of both PKD1 and PKD2 ("double hit")
e. None of the above

Acknowledgments This work was supported by a research grant from "Forschungsunterstützungskreis Kindernephrologie e.V."

\section{References}

1. Igarashi P, Somlo S (2002) Genetics and pathogenesis of polycystic kidney disease. J Am Soc Nephrol 13:2384-2398

2. Dell KM (2011) The spectrum of polycystic kidney disease in children. Adv Chronic Kidney Dis 18:339-347

3. Sweeney WE Jr, Avner ED (2011) Diagnosis and management of childhood polycystic kidney disease. Pediatr Nephrol 26:675-692

4. Dell KM, Sweeney WE, Avner ED (2009) Polycystic kidney disease. In: Avner ED, Harmon WE, Niaudet P, Yoshikawa N (eds) Pediatric nephrology, vol 1. Springer, Berlin, pp 849-887

5. Dias NF, Lanzarini V, Onunchic LF, Koch VH (2010) Clinical aspects of autosomal recessive polycystic kidney disease. J Bras Nefrol 32:263-267

6. Rossetti S, Harris PC (2007) Genotype-phenotype correlations in autosomal dominant and autosomal recessive polycystic kidney disease. J Am Soc Nephrol 18:1374-1380

7. Arbeiter A, Büscher R, Bonzel KE, Wingen AM, Vester U, Wohlschläger J, Zerres K, Nürnberger J, Bergmann C, Hoyer PF (2008) Nephrectomy in an autosomal recessive polycystic kidney disease (ARPKD) patient with rapid kidney enlargement and increased expression of EGFR. Nephrol Dial Transplant 23:3026-3029

8. Bergmann C, Senderek J, Sedlacek B, Pegiazoglou I, Puglia P, Eggermann T, Rudnik-Schöneborn S, Furu L, Onuchic LF, De Baca M, Germino GG, Guay-Woodford L, Somlo S, Moser M, Buttner R, Zerres K (2003) Spectrum of mutations in the gene for autosomal recessive polycystic kidney disease (ARPKD/PKHD1). J Am Soc Nephrol 14:76-89
9. Bergmann C, Senderek J, Windelen E, Küpper F, Middeldorf I, Schneider F, Dornia C, Rudnik-Schöneborn S, Konrad M, Schmitt CP, Seeman T, Neuhaus T, Vester U, Kirfel J, Büttner R, Zerres K, members of the APN (Arbeitsgemeinschaft für Pädiatrische Nephrologie (2005) Clinical consequences of PKHD1 mutations in 164 patients with autosomale-recessive polycystic kidney disease (ARPKD). Kidney Int 67:829-848

10. Furu L, Onuchic LF, Gharavi A, Hou X, Esquivel EL, Nagasawa Y, Bergmann C, Senerek J, Zerres K, Germino GG, Guay-Woodford LM, Somlo S (2003) Milder presentation of recessive polycystic kidney disease requires presence of amino acid substitution mutations. J Am Soc Nephrol 14:2004-2014

11. Guay-Woodford LM, Desomond RA (2003) Autosomal recessive polycystic kidney disease: the clinical experience in North America. Pediatrics 111:1072-1080

12. Srinath A, Shneider BL (2012) Congenital hepatic fibrosis and autosomal recessive polycystic kidney disease. J Pediatr Gastroenterol Nutr 54:580-587

13. Gunay-Aygun M, Font-Montgomery E, Lukose L, Tuchman Gerstein M, Piwnica-Worms K, Choyke P, Daryanani KT, Turkbey B, Fischer R, Bernadini I, Sincan M, Zhao X, Sandler NG, Roque A, Douek DC, Graf J, Huizing M, Bryant JC, Mohan P, Gahl WA, Heller T (2013) Characteristics of congenital hepatic fibrosis in a large cohort of patients with autosomal recessive polycystic kidney disease. Gastroenterology 144:112-121

14. Zerres K, Rudnik-Schoneborn S, Deget F, Holtkamp U, Brodehl J, Geisert J, Scharer K (1996) Autosomal recessive polycystic kidney disease in 115 children: clinical presentation, course and influence of gender: Arbeitsgemeinschaft für Pädiatrische Nephrologie. Acta Pediatr 85:437-445

15. Davis ID, Ho M, Huppertz V, Avner ED (2003) Survival of childhood polycystic kidney disease following renal transplantation: the impact of advanced hepatobiliary disease. Pediatr Transplant 7:364-369

16. Turkbey B, Ocak I, Daryanani K, Font-Montgomery E, Lukose L, Bryant J, Tuchman M, Mohan P, Heller T, Gahl WA, Choyke PL, Gunay-Aygun M (2009) Autosomal recessive polycystic kidney disease and congenital hepatic fibrosis (ARPKD/CHF). Pediatr Radiol 39:100-111

17. Shneider BL, Magid MS (2005) Liver disease in autosomal recessive polycystic kidney disease. Pediatr Transplant 9:634-639

18. Zerres K, Mucher G, Becker J, Steinkamm C, Rudnik-Schoneborn S, Heikkila P, Rapola J, Salonen R, Germino GG, Onuchic L, Somlo S, Avner ED, Harman LA, Stockwin JM, Guay-Woodford LM (1998) Prenatal diagnosis of autosomal recessive polycystic kidney disease (ARPKD): molecular genetics, clinical experience, and fetal morphology. Am J Med Genet 76:137-144

19. Adeva M, El-Youssef M, Rossetti S, Kamath PS, Kubly V, Consugar MB, Milliner DM, King BF, Torres VE, Harris PC (2006) Clinical and molecular characterization defines a broadened spectrum of autosomal recessive polycystic kidney disease (ARPKD). Medicine 85:1-21

20. Telega G, Cronin D, Avner ED (2013) New approaches to the autosomal recessive polycystic kidney disease patient with dual kidney-liver complications. Pediatr Transplant 17:328-335

21. Tsimaratos M, Cloarec S, Roquelaure B, Retornaz K, Picon G, Chabrol B, Guys JM, Sarles J, Nivet H (2000) Chronic renal failure and portal hypertension - is portosystemic shunt indicated? Pediatr Nephrol 14:856-858

22. Gabow P (1993) Autosomal dominant polycystic kidney disease. N Engl J Med 329:332-342

23. Gunay-Aygun M, Turkbey BI, Bryan J, Daryanani KT, Tuchman Gerstein M, Pivnica-Worms K, Choyke P, Heller T, Gahl WA (2011) Hepatorenal findings in obligate heterozygotes for autosomal recessive polycystic kidney disease. Mol Genet Metab 104:677-681

24. Vester U, Kranz B, Hoyer PF (2010) The diagnostic value of ultrasound in cystic kidney disease. Pediatr Nephrol 25:231-240 
25. Capisonda R, Phan V, Traubuci J, Daneman A, Balfe JW, GuayWoodford LM (2003) Autosomal recessive polycystic kidney disease: outcomes from a single-center experience. Pediatr Nephrol 18:119-126

26. Gagnadoux MF, Habib R, Levy M, Brunelle F, Broyer M (1989) Cystic renal diseases in children. Adv Nephrol Necker Hosp 18:33-57

27. Zerres K, Volpel MC, Weiss H (1984) Cystic kidneys: genetics, pathologic anatomy, clinical picture, and prenatal diagnosis. Hum Genet 68:104-135

28. Kaplan B, Fay J, Shah V (1989) Autosomal recessive polycystic kidney disease. Pediatr Nephrol 3:43-49

29. Rohatgi R, Zavilowitz B, Vergara M, Woda C, Kim P, Satlin LM (2005) Cyst fluid composition in human autosomal recessive polycystic kidney disease. Pediatr Nephrol 20:552-553

30. Chapman AB, Gabow PA (1997) Hypertension in autosomal dominant polycystic kidney disease. Kidney Int Suppl 61:S71-S73

31. Goto M, Hoxha N, Osman R, Dell KM (2010) The reninangiotensin-system and hypertension in autosomal recessive polycystic kidney disease. Pediatr Nephrol 25:2449-2457

32. Torres VE, Harris PC (2009) Autosomal dominant polycystic kidney disease: the last 3 years. Kidney Int 76:149-168

33. Yi L, Naruse S, Furuya S, Yamamoto A, Nakakuki M, Nagao S, Yoshihara D, Ko SB, Wei M, Kondo T, Ishiguro H (2012) Structure and function of the pancreas in the polycystic kidney rat. Pancreas 41: 1292-1298

34. Torra R, Nicolau C, Badenas C, Navarro S, Perez L, Estivill X, Darnell A (1997) Ultrasonographic study of pancreatic cysts in autosomal dominant polycystic kidney disease. Clin Nephrol 47:19-22

35. Nicolau C, Torra R, Bianchi L, Vilana R, Gilabert R, Darnell A, Brú C (2000) Abdominal sonographic study of autosomal dominant polycystic kidney disease. J Clin Ultrasound 28:277-282

36. Guettier C (2010) Intrahepatic biliary cystic lesions. Ann Pathol 30: 448-454

37. Mehler K, Beck BB, Kaul I, Rahimi I, Hoppe B, Kribs A (2011) Respiratory and general outcome in neonates with renal oligohydramnios - a single-centre experience. Nephrol Dial Transplant 26:3514-3522

38. Klaassen I, Neuhaus TJ, Mueller-Wiefel DE, Kemper M (2007) Antenatal oligohydramnios of renal origin: long-term outcome. Nephrol Dial Transplant 22:432-439

39. Smith NP, Losty PD, Connell MG, Mayer U, Jesudason EC (2006) Abnormal lung development precedes oligohydramnios in a transgenic murine model of renal dysgenesis. J Urol 175:783-786

40. dos Santos JM, Ferreira AR, Fagundes ED, Ferreira AP, Ferreira LS, Magalhães MC, Bittencourt PF, Carvalho SD, Figueiredo Filho PP, Penna FJ (2013) Endoscopic and pharmacological secondary prophylaxis in children and adolescents with esophageal varices. J Pediatr Gastroenterol Nutr 56:93-98

41. Brinkert F, Lehnhardt A, Montoya C, Helmke K, Schaefer H, Fischer L, Nashan B, Bergmann C, Ganschow R, Kemper MJ (2013) Combined liver-kidney transplantation for children with autosomal recessive polycystic kidney disease (ARPKD): indication and outcome. Transpl Int 26:640-650

42. Büscher R, Wingen AM, Büscher AK, Kranz B, Vester U, Hoyer PF (2011) Erfahrungen mit kombinierter Leber-/Nierentransplantation bei Kindern mit Oxalose und ARPKD. Monatsschr Kinderheilkd 159[Suppl 3]:152

43. Jalanko H, Pakarinen M (2013) Combined liver and kidney transplantation in children. Pediatr Nephrol. doi:10.1007/s00467-013-2487-7

44. Torres VE (2004) Therapies to slow polycystic kidney disease. Nephron Exp Nephrol 98:e1-e7

45. Gattone VH 2nd, Wang X, Harris PC, Torres VE (2003) Inhibition of renal cystic disease development and progression by a vasopressin V2 receptor antagonist. Nat Med 9:1323-1326

46. Shillingford JM, Murcia NS, Larson CH, Low SH, Hedgepeth R, Brown N, Flask CA, Novick AC, Goldfarb DA, Kramer-Zucker A, Walz G, Piontek KB, Germino GG, Weimbs T (2006) The mTOR pathway is regulated by polycystin-1, and its inhibition reverses renal cystogenesis in polycystic kidney disease. Proc Natl Acad Sci USA 103:5466-5471

47. Masyuk TV, Radtke BN, Stroope AJ, Banales JM, Gradilone SA, Huang B, Masyuk AI, Hogan MC, Torres VE, LaRusso NF (2013) Pasireotide is more effective than octreotide in reducing hepatorenal cystogenesis in rodents with polycystic kidney and liver diseases. Hepatology 58:409-421

48. Masoumi A, Reed-Gitomer B, Kelleher C, Schrier RW (2007) Potential pharmacological interventions in polycystic kidney disease. Drugs 67:2495-2510

49. Renken C, Fischer DC, Kundt G, Gretz N, Haffner D (2011) Inhibition of mTOR with sirolimus does not attenuate progression of liver and kidney disease in PCK rats. Nephrol Dial Transplant 26: $92-100$

50. Zing-Schenk A, Caduff J, Azzarello-Burri S, Bergmann C, Drenth JPH, Neuhaus T (2012) Boy with autosomal recessive polycystic kidney disease and autosomal dominant polycystic liver disease. Pediatr Nephrol 27:1197-1200

51. Fonck C, Chauveau D, Gagnadoux M-F, Pirson Y, Grunfeld J-P (2001) Autosomal recessive polycystic kidney disease in adulthood. Nephrol Dial Transplant 16:1648-1652

52. Neumann HP, Krumme B, van Velthoven V, Orszagh M, Zerres K (1999) Multiple incranial aneurysms in a patient with autosomal recessive polycystic kidney disease. Nephrol Dial Transplant 14: 936-939

53. Lilova MI, Petkov DL (2001) Intracranial aneurysms in a child with autosomal recessive polycystic kidney disease. Pediatr Nephrol 16: $1030-1032$

54. Chalhoub V, Abi-Rafeh L, Hachem K, Ayoub E, Yazbeck P (2013) Intracranial aneurysm and recessive polycystic kidney disease. JAMA Neurol 70:114-116

\section{Answers:}

1) $b$

2) c

3) e

4) d

5) d 